\title{
Percutaneous aspiration of lumbar zygapophyseal joint synovial cyst under fluoroscopic guidance -A case report-
}

\author{
Keun-Man Shin ${ }^{1}$, Myoung-Sun Kim ${ }^{1}$, Kwang-Min Ko ${ }^{1}$, Ji-Su Jang ${ }^{2}$, Sang-Soo Kang ${ }^{1}$, and Sung-Jun Hong \\ Department of Anesthesiology and Pain Medicine, ${ }^{1}$ Kang-Dong Sacred Heart Hospital, Seoul, ${ }^{2}$ Chuncheon Sacred Heart Hospital, \\ Hallym University College of Medicine, Chuncheon, Korea
}

A 51-year-old man with a 1-month history of lower back pain and radiating pain visited to our pain clinic. A magnetic resonance imaging (MRI) scan demonstrated a cyst like mass at the level of the L4-5 interspace and compression of the thecal sac and the nerve root on the right side. We performed percutaneous needle aspiration of the lumbar zygapophyseal joint synovial cyst under fluoroscopic guidance. The patient felt an immediate relief of symptoms after the aspiration, and had no signs or symptoms of recurrence at the follow-up 6 months later. No demonstrable lesion was found in the 6 months follow-up MRI. (Korean J Anesthesiol 2012; 62: 375-378)

Key Words: Fluoroscopic guidance, Low back pain, Zygapophyseal joint synovial cyst.

Synovial cysts from the capsule of a lumbar zygapophysial joint (Z-joint) can produce symptoms consistent with an extradural space-occupying lesion. These symptoms, include axial pain, and radiculopathy. Traditional interventions include either conservative or surgical management $[1,2]$. A variety of minimally invasive percutaneous Z-joint [3-5] and intracystic procedures have been employed [6-9]. This report introduces a minimally invasive technique for treating synovial cysts.

\section{Case Report}

The patient was a 51-year-old man with a 1-month history of lower back pain. At the onset, the pain radiated to the right buttock with a tingling sensation down his right lower limb posteriorly to his ankle. He also complained of numbness in his right foot. The pain was aggravated by sitting and standing, coughing, and sneezing. He did not report any difficulty with bowel, bladder, or sexual function. On physical examination, a straight leg-raising test of the right leg was positive at 60 degrees. The deep tendon reflexes were $2+$ on the both knees and ankles.

A magnetic resonance imaging (MRI) scan demonstrated a mass at the level of the L4-5 interspace and, compression of the thecal sac and the nerve root on the right side (Fig. 1); it was not possible to determine whether the lesion was completely extradural or partially intradural. Owing to the signal characteristics, a synovial cyst arising from the medial aspect of the facet joint was suspected to adhere to the entire length of the nerve root sleeve.

Received: April 6, 2011. Revised: June 23, 2011. Accepted: August 8, 2011.

Corresponding author: Sung-Jun Hong, M.D., Department of Anesthesiology and Pain Medicine, Kang-Dong Sacred Heart Hospital, Hallym University Medical Center, 445, Gil-dong, Kangdong-gu, Seoul 134-701, Korea. Tel: 82-2-2224-2659, Fax: 82-2-474-0956, E-mail: 69hsj@naver.com (C)This is an open-access article distributed under the terms of the Creative Commons Attribution Non-Commercial License (http:// creativecommons.org/licenses/by-nc/3.0/), which permits unrestricted non-commercial use, distribution, and reproduction in any medium, provided the original work is properly cited. 

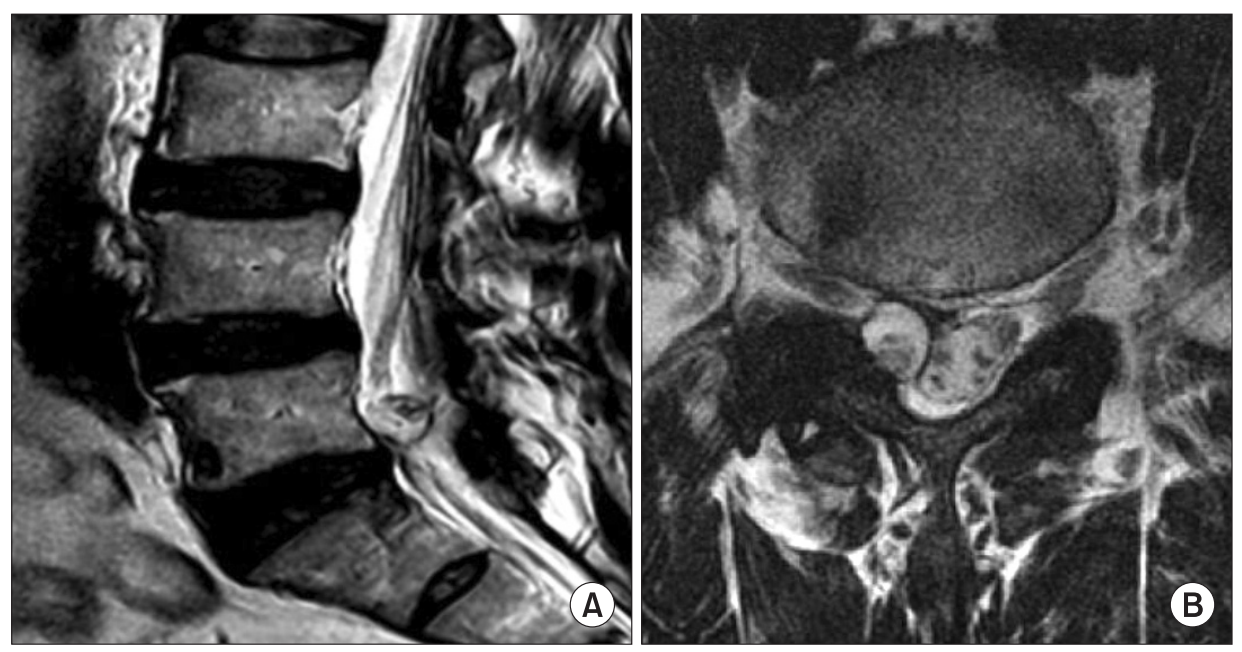

Fig. 1. This figure shows the sagittal and axial magnetic resonance images of the lumbar spine. The proton-weighted sagittal image of the lumbar spine (A) demonstrates the presence of a large mass at the level of the lower part of the L5 body. In the T2-weighted axial view (B) the mass appears to be medial to the facet joint. A peripheral zone of calcification surrounds the mass. The central lucency might be air or fat. The appearance is compatible with a synovial cyst arising from the facet joint.
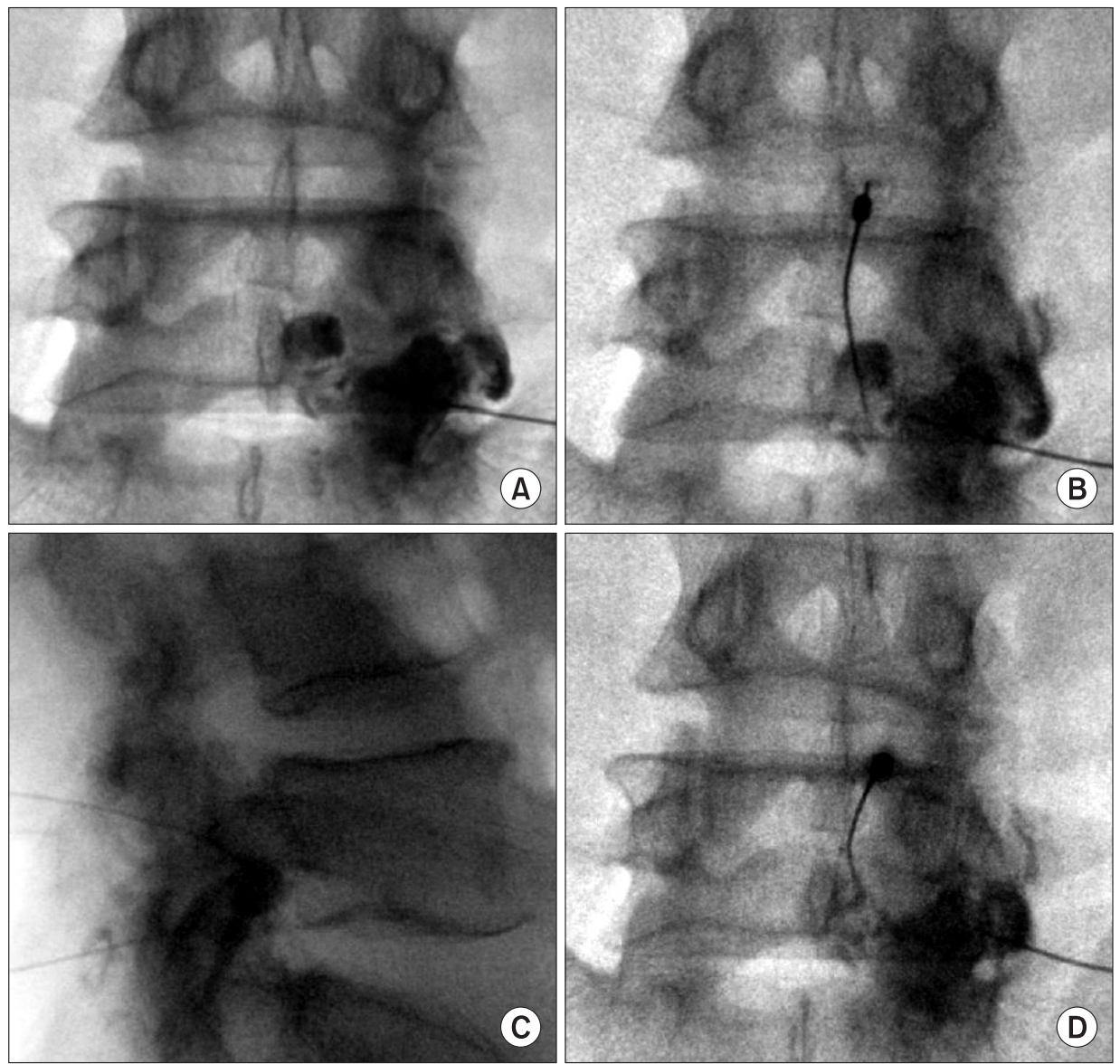

Fig. 2. This figure shows a fluoroscopic view of a synovial cyst distention (A), a second spinal needle in the cyst $(B, C)$, and a fluoroscopic view of Z-point cyst rupture with epidural spread (D).

The patient was placed in the prone position on the procedure table. The skin entry point was anesthetized. A 22-gauge 3.5-inch spinal needle was advanced under fluoroscopic guidance into the right L5/S1 zygapophysial joint. By injecting the right L5/S1 zygapophysial joint with contrast, a right synovial cyst was identified under fluoroscopy. A second 22-gauge 3.5-inch spinal needle was introduced into the cyst directly with a right paramedian, interlaminar approach under fluoroscopic guidance (Fig. 2). Serosanguinous fluid $1.0 \mathrm{ml}$ was aspirated, and triamcinolone acetate $10 \mathrm{mg}$ was injected into the cyst. The patient felt an immediate relief of symptoms after the aspiration, and had no signs or symptoms of recurrence 

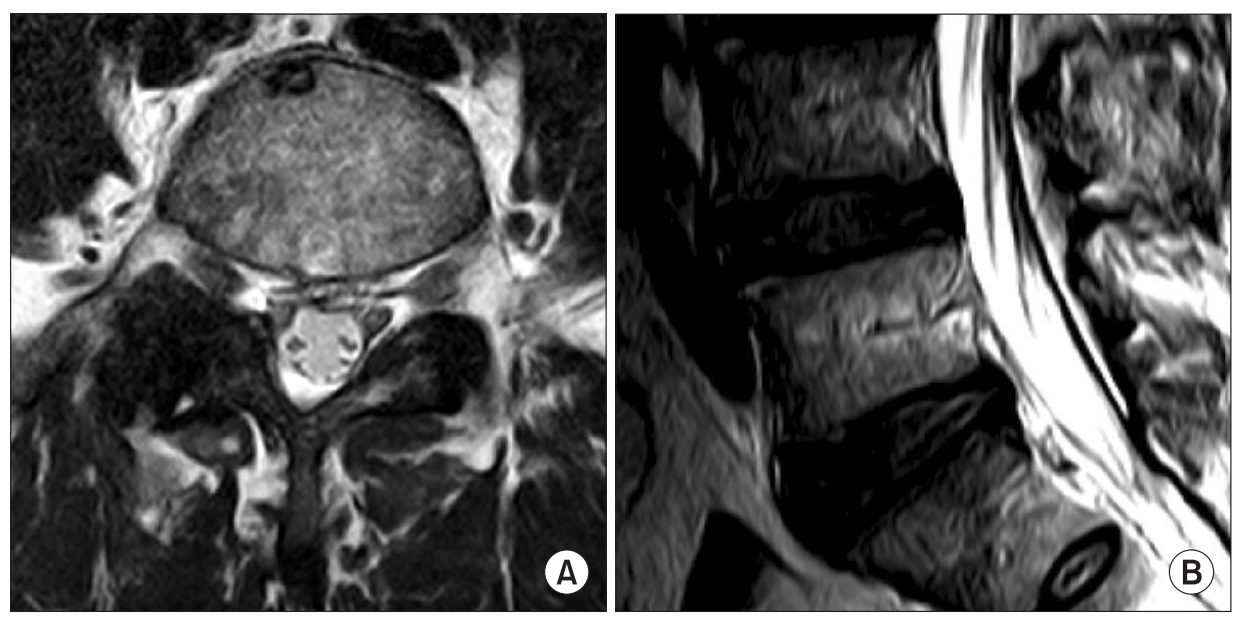

Fig. 3. This figure shows sagittal (A) and axial (B) magnetic resonance images of the lumbar spine 6 months after cyst aspiration.

at the follow-up 6 months later. No demonstrable lesion was found in the 6 months follow-up MRI (Fig. 3).

\section{Discussion}

Lumbar Z-joint synovial cysts usually originate from the Z-joint capsule. The cyst can be lined with synovium and contain serous, gelatinous, or hemorrhagic fluid [10]. The development of Z-joint synovial cysts is linked to degenerative spondylosis, segmental instability and perhaps trauma [1]. At least $1 \%$ of all lumbar radicular pain may be the result of Z-joint synovial cysts [10]. Z-joint synovial cysts are frequently associated with a narrowed spinal canal caused by stenosis, so Z-joint synovial cysts easily become symptomatic [11].

Accurate diagnosis of $\mathrm{Z}$-joint synovial cyst results in a number of therapeutic implications. Facet joint injection with steroid and long-acting anesthetic can provide temporary or prolonged pain relief $[3,4,12]$ which may be of value in patients unfit for surgery. Indirect aspiration via the facet joint can be effective, and direct aspiration under fluoroscopic guidance has been successful [12]. Surgery, to relieve sciatica caused by a Z-joint synovial cyst is effective in a high proportion of patients $[2,4]$. Minimally invasive techniques for the treatment of lumbar synovial cyst seem to eliminate many of the risks of traditional surgical techniques [13]. In this case, direct needle aspiration of the cyst was performed, and this less invasive procedure may be employed as an alternative to surgery. Since the cyst may spontaneously decompress, conservative treatment can be beneficial. However, surgery may be required if this treatment fails [13].

Z-joint synovial cysts are treated with an interlaminar or intra-articular approach. Direct cyst puncture may cause a dural puncture if performed using a translaminar approach. Most of the reports prefer an intra-articular approach in performing cyst aspiration [10]. However, in using the intra-articular approach, aspiration of cyst fluid is often difficult because of the relative ball-valve effect, which occurs as negative pressure is applied. Bureau et al. [5] described a technique used to rupture the cyst by injecting the joint or inferior joint recess with as much as $3 \mathrm{ml}$ of betamethasone and bupivacaine, followed by $1-5 \mathrm{ml}$ injection of normal saline. Rupture of the cyst was accomplished in $50 \%$ of cases, with pain relief in 9 out of 12 patients.

Researchers have attempted interventions involving the Z-joint synovial cyst itself. Jacob et al. [6] introduced a 20-gauge spinal needle into the cyst and aspirated $1.0 \mathrm{ml}$ of fluid under CT guidance. Dexamethasone $0.5 \mathrm{ml}$ was infused directly into the cyst. The patient was asymptomatic within 3 days, and remained pain free at the 18-month follow- up. Koenigsberg [7] positioned a 22-gauge spinal needle into the cyst and fluid was aspirated under CT guidance with no contrast solution used. The patient had immediate partial pain relief, followed by complete relief on the third day following the procedure. MRI at the 10-day follow up showed collapse of the cyst. Lim et al. [8] passed a 22-gauge needle into a cyst under CT guidance, and injected $20 \mathrm{mg}$ of triamcinolone and $1 \mathrm{ml}$ of bupivacaine. The patient reported immediate complete relief of pain, and remained pain-free for 9 months after the treatment. After multiple interventions to aspirate and drain the cyst through the Z-joint, Gishen and Miller [9] used CT guidance to aspirate the cyst through the lamina with a bone biopsy needle. Long-term resolution of symptoms occurred and MRI taken after a year showed no recurrence. Complete regression of the cyst seems to occur only with complete rupture [5].

In our patient, direct puncture of the cyst was accomplished using an interlaminar approach with fluoroscopic guidance. Cyst puncture was performed with live fluoroscopy, to ensure the position of the needle within the contrast-filled cyst. The patient derived complete resolution of his right limb radicular pain after puncture of a Z-joint synovial cyst and remained 
pain-free at the 6 month follow-up. The patient had no dural puncture, or any additional complications.

\section{References}

1. Sabo RA, Tracy PT, Weinger JM. A series of 60 juxtafacet cysts: clinical presentation, the role of spinal instability, and treatment. J Neurosurg 1996; 85: 560-5.

2. Freidberg SR, Fellows T, Thomas CB, Mancall AC. Experience with symptomatic spinal epidural cysts. Neurosurgery 1994; 34: 989-93.

3. Bjorkengren AG, Kurz LT, Resnick D, Sartoris DJ, Garfin SR. Symptomatic intraspinal synovial cysts: opacification and treatment by percutaneous injection. AJR Am J Roentgenol 1987; 149: 105-7.

4. Reust P, Wendling D, Lagier R, Pageaut G, Reverdin A, Jacquet G, et al. Degenerative spondylolisthesis, synovial cyst of the zygapophyseal joints, and sciatic syndrome: report of two cases and review of the literature. Arthritis Rheum 1988; 31: 288-94.

5. Bureau NJ, Kaplan PA, Dussault RG. Lumbar facet joint synovial cyst: percutaneous treatment with steroid injections and distention--Clinical and imaging follow-up in 12 patients. Radiology 2001; 221: 179-85.

6. Jacob JR, Weisman MH, Mink JH, Metzger AL, Feldman GR,
Dorfman HD, et al. Reversible cause of back pain and sciatica in rheumatoid arthritis: an apophyseal joint cyst. Arthritis Rheum 1986; 29: 431-5.

7. Koenigsberg RA. Percutaneous aspiration of lumbar synovial cyst: CT and MRI considerations. Neuroradiology 1998; 40: 272-3.

8. Lim AK, Higgins SJ, Saifuddin A, Lehovsky J. Symptomatic lumbar synovial cyst: management with direct CT-guided puncture and steroid injection. Clin Radiol 2001; 56: 990-3.

9. Gishen P, Miller FN. Percutaneous excision of a facet joint cyst under CT guidance. Cardiovasc Intervent Radiol 2001; 24: 351-3.

10. Shah RV, Lutz GE. Lumbar intraspinal synovial cysts: conservative management and review of the world's literature. Spine J 2003; 3: 479-88.

11. Jonsson B, Tufvesson A, Stromqvist B. Lumbar nerve root compression by intraspinal synovial cysts. Report of 8 cases. Acta Orthop Scand 1999; 70: 203-6.

12. Hong Y, O'Grady T, Carlsson C, Casey J, Clements D. Percutaneous aspiration of lumbar facet synovial cyst. Anesthesiology 1995: 82: 1061-2.

13. Sandhu FA, Santiago P, Fessler RG, Palmer S. Minimally invasive surgical treatment of lumbar synovial cysts. Neurosurgery 2004; 54: $107-11$. 